\title{
Conexões
}

Educação Física, Esporte e Saúde

\section{Corpo e cultura: políticas e cotidiano da formação em Educação Física}

\author{
José Luiz Cirqueira Falcão ${ }^{1}$
}

\section{RESUMO}

O objetivo desse ensaio foi fazer uma análise das políticas de formação em educação física, tendo como foco o diálogo entre o corpo e a cultura, a partir dos trabalhos e possibilidades de análise construídos dentro do Grupo de Trabalho Temático Corpo e Cultura do Colégio Brasileiro de Ciências do Esporte (GTTCC/CBCE).

Palavras-Chave: Corpo. Cultura. Formação em educação física.

\footnotetext{
${ }^{1}$ Universidade Federal de Goiás

Recebido em: 8 maio 2018

Aprovado em: 30 jun, 2018

Contato: joseluizfalcao@hotmail.com.br
} 


\section{Body and culture: political and everyday training in Physical Education}

\section{ABstract}

The objective of this essay was to make an analysis of training policies in physical education, focusing on the dialogue between the body and the culture, based on the work and analysis possibilities built within the Body and Culture Thematic Working Group of the Brazilian College of Sport Sciences (GTTCC / CBCE).

Keywords: Body. Culture. Physica education training.

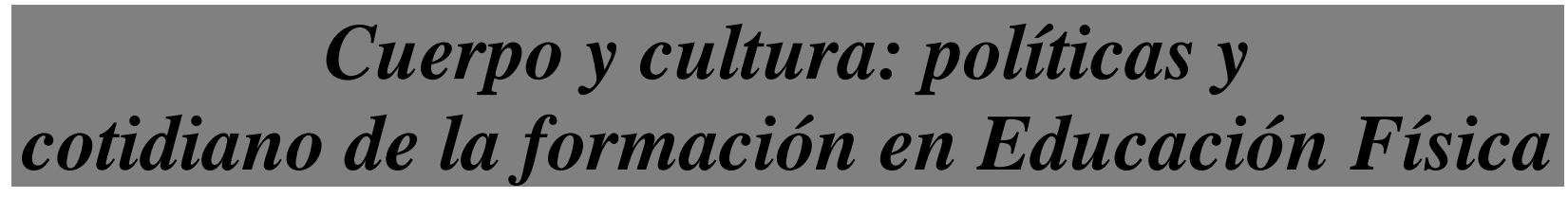

\section{RESUMEN}

El objetivo de este ensayo fue hacer un análisis de las políticas de formación en eeudcación física, teniendo como foco, el diálogo entre el cuerpo y la cultura, a partir de los trabajos y posibilidades de análisis construidas dentro del Grupo de Trabajo Temático Cuerpo y Cultura del Colegio Brasileño de Ciencias del Deporte (GTTCC / CBCE).

Palabras Clave: Cuerpo. Cultura. Formación en educación física. 


\section{INTRODUÇÃO}

Antes de problematizar conceitualmente, dentro dos meus limites teóricos, as palavraschaves que compõem esse importante tema, quais sejam: corpo, cultura, política, cotidiano e formação, nesse caso, formação em Educação Física, ilustrarei a introdução da minha fala com uma cantiga conhecida nas rodas de capoeira, de autoria de um mestre do Rio de Janeiro, chamado Toni Vargas. A ideia é demonstrar a riqueza das lições e dos saberes, expressos em seus versos que, por sua vez e de certa forma, também contribuem, em conjunto com outros procedimentos que compõem o ritual da roda de capoeira, para a formação e o esclarecimento de significativa parcela da comunidade capoeirana. Cumpre notar que, na maioria dos casos, a capoeira não encontra nas instituições educacionais um campo fértil e acolhedor capaz de "dialo(jo)gar" com suas malicias e mandingas.

A intenção é chamar a atenção para vários elementos de formação que compõem as práticas corporais populares e que ainda são tratados pedagogicamente de forma muito humilde pelas instituições escolares, em geral e pela Educação Física, em particular. Em muitos casos essas instituições estão mais preocupadas com conceitos e formulações rebuscados que não estimulam, não sensibilizam e, por vezes, mais confundem do que esclarecem os sujeitos envolvidos. Alguns trechos da cantiga do referido Mestre foram adaptados para esse momento. Senão vejamos:

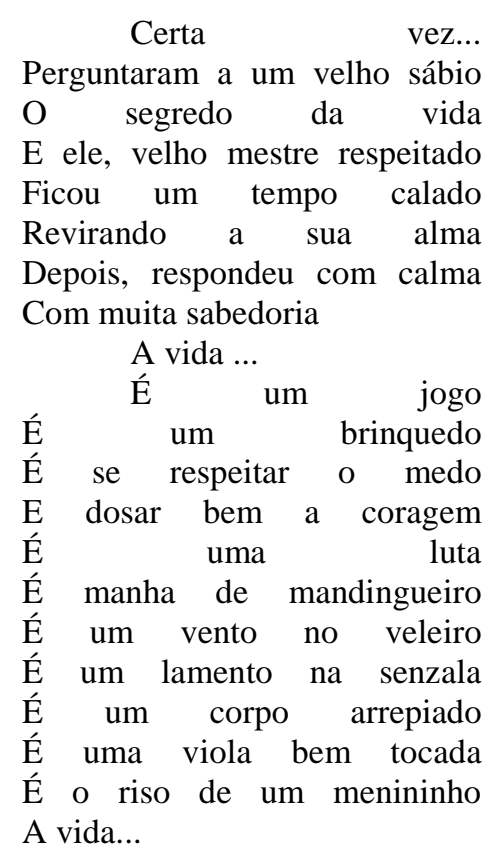

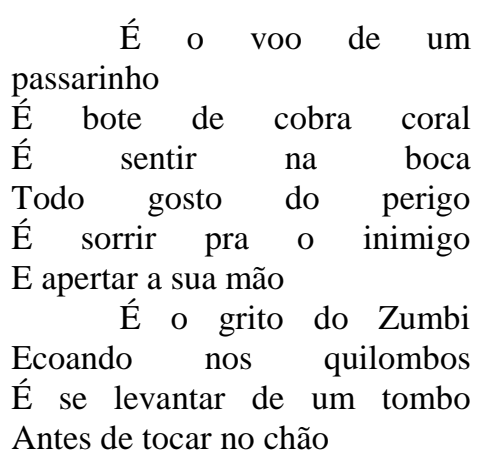

Antes de tocar no chão

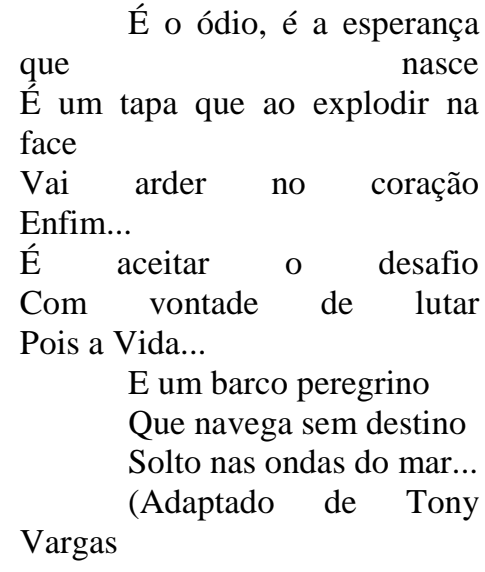


A partir desse canto reflexivo, procurarei articular os conceitos que embasam esta temática, utilizando-me de experiências do "concreto vivido", com o intuito de buscar esclarecimentos necessários para qualificar o debate teórico e, principalmente, para contribuir com o avanço da teoria pedagógica da Educação Física.

\section{Políticas e Cotidiano da Formação em EDUCAÇÃo FísICA}

Para discutir conceitualmente os temas pilares, procurarei fazê-lo utilizando-me, principalmente de conceitos formulados por quatro pensadores, sem negar, obviamente, a contribuição de tantos outros, chamando a atenção para o caráter relacional da experiência humana, numa época em que o cinismo e o pragmatismo imperam pomposamente. São eles, o filósofo italiano Antonio Gramsci (22/01/1891 - 27/04/1937), o sociólogo português Machado Pais, o antropólogo Francês Denys Cuche e o educador brasileiro Paulo Freire (19/09/1921 - 02/05/1997).

Esses autores citados se tornaram e são referências na comunidade científica pela discussão acumulada e pela contribuição teórica acerca desses temas que, neste seminário, serão debatidos e problematizados. A partir de diferentes contextos e matrizes teóricas, esses pensadores se debruçaram sobre esses temas e o nosso desafio aqui é colocá-los em tensão, articulá-los e buscar elementos de superação para a orientação da nossa teoria e da nossa prática pedagógica, hoje tão vazias de utopias e ideologias. Cabe aqui lembrar o verso do nosso canto inicial: A vida... É o grito de Zumbi ecoando no quilombo, é se levantar do tombo antes de tocar no chão...

É fundamental destacar o caráter extremamente inter-relacional desses temas, já que não existe corpo humano sem cultura e vice-versa e que esses não existem à revelia de fatos políticos e do cotidiano. Embora convivamos, como nunca, com a fragmentação do conhecimento, é importante considerar, que na sociedade capitalista hodierna, os interesses individuais estão submetidos aos valores das classes dominantes disfarçados de valores gerais. O ideário burguês capitalista, que se baseia no fato de que todas as necessidades e interesses humanos são estritamente individuais, só mascara que os mesmos são condicionados pelos interesses das classes dominantes. Mesmo que os indivíduos possam ser desinteressados, e frequentemente o são, os grupos sociais e as classes não o são, nem poderiam ser, pois eles se encontram diante de problemas (interesses e necessidades) que são questões de vida ou de morte. As guerras entre nações, de caráter imperialista, são exemplos clássicos. 
Por isso, não podemos aceitar a ingenuidade e a ilusão de que, se cada um fizer a sua parte, tudo estará resolvido. Embora não tenhamos pretensões totalizantes nem acreditamos em ideologias salvacionistas, destacamos que é preciso buscar articulações sempre, inclusive no plano teórico. Obviamente, essa articulação poderia ser realizada com o suporte de vários outros pensadores que também discorrem sobre essas temáticas. A opção aqui adotada, além de externar os nossos limites, tem também um apelo didático, cuja intenção é facilitar o entendimento, apontar novas perspectivas para pensar a formação em Educação Física numa perspectiva político-cultural e, sobretudo, buscar novos horizontes teóricos para tratar a prática pedagógica nesse campo.

A rigor, é fundamental deixar claro aqui que não falamos de qualquer lugar. Todos esses conceitos e temas devem ser contextualizados e cotejados com as experiências do cotidiano em que a velocidade, a volatilidade e a instabilidade transformaram-se em regras de convivência.

Sendo assim, ressalto que o nosso diálogo, em não sendo neutro, também não é idealista. Cotejaremos os conceitos formulados pelos autores citados com o contexto em que vivemos, retomando, sempre que possível, a exemplos concretos da realidade vivida no campo da formação em Educação Física. Não estamos interessados nos estudos das formas de manutenção, conservação, sustentação ou reprodução do status quo, estamos, sim, buscando uma sintonia com os estudos que advogam a transformação do modelo de produção da vida, com a superação do modelo sócio metabólico do capital (capitalismo transnacional e seu braço operacional - o neoliberalismo). Este, por sua vez, vem emplacando irreversível destrutividade, como demonstram as condições de vida cada vez mais deterioradas de significativa parcela da humanidade, com tendência já visível a uma total destruição, apesar de convivermos com uma minoria com níveis altíssimos de bem-estar e transformações jamais vistas anteriormente.

O mais delicado, para não dizer, mais complicado nesse processo é constatar que muitos intelectuais, "em retirada", sequer cogitam em seus primorosos "papers", os dados e os reflexos dessa barbárie em que vivemos. Urge, no nosso ponto de vista, a necessidade de enfrentar essa realidade por meio de articuladas ações capazes de reorientar o processo civilizatório e evitar, assim, um colapso mundial, à medida que vivemos sob a "tirania do dinheiro e da informação totalitária" (SANTOS, 2000). Os dados da realidade demonstram que esses fenômenos vêm contribuindo para o empobrecimento crescente das massas e para a esterilização e destruição de vidas.

Necessário se faz nesse momento pontuar algumas questões de fundo que resistem em se calar. Que mundo queremos para nós? Que mundo deixaremos para as próximas gerações? É o mundo do capital financeiro globalizado? É o das coalizões militares imperialistas? É o das máfias criminosas de todos os quilates? É o mundo das franquias e dos merchandisings? É o mundo dos cyborgs mais rápidos, mais fortes, mais ágeis, controlados pelos poderosos e 
invisíveis anabolizantes? Ou um mundo justo, como realidade histórica unitária, ainda que extremamente diversificada?

Precisamos ter clareza que o quadro configurado pelo sistema capitalista e construído a reboque de maciça ideologização está se impondo como "uma fábrica de perversidades" e exige, para se manter, o "exercício de fabulações" (SANTOS, 2000). Mas, essa perversidade, nos moldes como se configura na atualidade, não é um fenômeno irreversível.

Para construir um novo sentido de felicidade individual e coletiva, a humanidade deve considerar as possibilidades efetivamente criadas a partir das disponibilidades postas pelas condições materiais concretas, onde a política tem papel preponderante na relação disponibilidade/possibilidade. Numa perspectiva otimista, o geógrafo brasileiro, reconhecido internacionalmente, Milton Santos advoga, em seus escritos, a necessidade de integração de duas grandes mutações que ora se encontram em gestação - "a mutação tecnológica e a mutação filosófica da espécie humana" (SANTOS, 2000, p. 174).

Retomando o fio condutor e os autores que nos auxiliam nessa fala, gostaria, sem medo de ser tachado de dinossauro obsoleto, de inicialmente dialogar com as formulações teóricas do pensador italiano Antonio Gramsci, autor dos Cadernos do Cárcere. Elas foram elaboradas em condições extremas, na prisão, e nos legaram muitos ensinamentos que atualmente são propalados pelos intelectuais institucionais como anacrônicos, vazios de conteúdos, ou simplesmente blábláblá. Aliás, os conceitos de dominação ideológica (subordinação intelectual), concepção de mundo, senso comum, bom senso, filosofia da práxis, intelectuais orgânicos, hegemonia, bloco histórico, sociedade civil, sociedade política, reforma intelectual e moral e elevação cultural das massas, entre outros, são ignorados e, na maioria dos casos, negados, pela sedução e pela ilusão das formulações teóricas pós-modernas - do irracionalismo, aos "giros" ou "viradas" idealistas. Na maioria dos casos, ao invés de esclarecer, essas formulações terminam por confundir e iludir aqueles que não são capazes de perceber as "imposturas intelectuais" e os recuos teóricos que "vêm desarmando a classe trabalhadora no campo e na cidade, contribuindo para a alienação" (TAFAREL, 2008, p. 1).

No modelo de sociedade capitalista, como é o caso da sociedade brasileira - com o distintivo de ser periférico, há uma produção de consenso social que aceita, ainda que com resistências, a direção que as classes dominantes dão a sociedade. A isso Gramsci chamou de dominação ideológica, ou subordinação intelectual. Essa possibilidade de dominação se dá basicamente, segundo Gramsci, por dois fatores: a interiorização da ideologia dominante pelas "classes subalternas", que aqui chamarei de classes exploradas, e a ausência de uma visão de mundo coerente e homogenia por parte dessas mesmas classes que lhes permitam o exercício da autonomia. Para Gramsci, as classes exploradas frequentemente estão atreladas, pelo conformismo, ao senso comum, à religião popular e às crendices. $\mathrm{O}$ senso comum, que para Gramsci é a filosofia dos não-filósofos, compõe-se de estratos acumulados de ideias correspondentes a fases históricas anteriores que permanecem anacrônicas e funcionam como 
uma base de sustentação da ideologia dominante. Caracteriza-se pela adesão irrestrita das massas a uma concepção de mundo forjada pelas classes dominantes que, graças a uma prodigiosa transposição de termos, conseguem transformar em "senso comum" a sua própria ideologia. As representações do mundo que esse senso comum permite são frequentemente ocasionais e desagregadas que se materializam como uma obediência irracional a princípios e preceitos que funcionam no plano da crença e da fé. Vejamos, por exemplo, a fantástica e controvertida trajetória histórica da capoeira. Se por um lado, à época da escravidão, ela era associada às lutas de negros escravizados em busca da liberdade, por outro, atualmente, ela tem sido vinculada majoritariamente à lógica do "sistema de sociometabolismo do capital" (MÉSZÁROS, 2002) 2), embora em moldes bem diferentes de outras práticas corporais que já nasceram sob o aporte da "tirania da informação e do dinheiro" (SANTOS, 2000), como o bodypump ${ }^{3}$, por exemplo.

Segundo Gramsci não existe um único senso comum. Como produto histórico, ele pode ser superado, pela crítica filosófica, possibilitando a construção do bom senso. O bom senso é, portanto, o núcleo sadio do senso comum e o instrumento para trabalhar esse núcleo de bom senso é, para Gramsci, a Filosofia da Práxis - expressão que usava com o intuito de iludir a censura fascista da prisão e que correspondia ao materialismo histórico e dialético formulado por Marx e Engels a partir da crítica das três correntes de pensamento mais avançados do século XIX: a economia política inglesa, a filosofia clássica alemã e o pensamento e a prática política socialistas franceses.

Para Gramsci, a filosofia da práxis deve ser operada a partir de duas ações concomitantes. A primeira consiste na crítica do senso comum, não desprezando nele o que há de bom senso. A segunda é a crítica das filosofias dos intelectuais, que deve ser sustentada e atualizada, sem banalizações.

É nesse contexto que entra em campo o que Gramsci chama de "intelectual orgânico", cuja função é levar às massas a filosofia da práxis, não de fora para dentro, mas articulando-a

\footnotetext{
2 Mészáros (2002) argumenta que o sistema de sociometabolismo do capital é muito poderoso, abrangente e incontrolável. Sem a superação do tripé que forma esse sistema articulado, embora assimétrico, capital, trabalho e Estado, é impossível emancipar o trabalho, e que as experiências revolucionárias vivenciadas no século passado, desde a Revolução Russa até as tentativas mais recentes de constituição societal socialista, se mostraram incapacitadas de superá-lo.

${ }^{3}$ Trata-se de um sistema de ginástica desenvolvido em forma de franquia (body systems), com sede na Nova Zelândia, cuja rede já atingiu, em apenas uma década de existência, nada menos que 42 (quarenta e dois) países, quatro mil academias, 12 (doze) mil professores que se "movimentam" em torno de um meticulosamente padronizado programa de ginástica. Esse "fitness inteligente" coloca massificadamente o corpo na era globalizada sob ilusórios e perversos mecanismos ideológicos que contribuem para alicerçar "o sistema ideológico que justifica as ações hegemônicas e leva ao império das fabulações, a percepções fragmentadas e ao discurso único do mundo, base dos novos totalitarismos - isto é, dos globalitarismos - a que estamos assistindo" (SANTOS, 2000, p. 38). O mesmo programa é desenvolvido tanto em Palmas, no Tocantins, como em Kyoto, no Japão, disseminando os mesmos modelos de exercícios, as mesmas músicas, a mesma estética e veiculando a ilusória ideia de que todos os seres do planeta apreciam as mesmas "novidades" e que são portadores das mesmas condições materiais de vida.
} 
com a reflexão que é possível a partir da prática cotidiana das massas e de sua luta política. São aqueles que se enfronham na vida prática das massas e difundem a concepção de mundo revolucionária, procurando elevar a consciência dispersa e fragmentária das massas ao nível de uma concepção de mundo coerente e homogênea.

Gramsci sugere que as camadas populares, cada vez mais numerosas, trabalhem na "criação de elites de intelectuais de novo tipo, que surgem diretamente da massa e que permaneçam em contato com ela para tornarem-se seus sustentáculos" (GRAMSCI, 1981, P. 27).

Outro conceito muito caro ao pensamento de Gramsci é o conceito de Hegemonia. Talvez, a mais importante contribuição desse pensador para a atualização da teoria marxista. Trata-se do conjunto de funções de domínio e direção intelectual e moral exercido por uma classe social dominante, no decurso de um período histórico, sobre outra classe social ou até sobre o conjunto das classes da sociedade.

Para Gramsci as concepções de mundo aparecem de dois modos: ocasional e desagregado, coerente e homogêneo. Para passar da consciência ocasional e desagregada para uma consciência coerente e homogênea é preciso criticar a concepção de mundo que se tem, partindo da consciência daquilo que somos e chegando "ao ponto atingido pelo pensamento mundial mais desenvolvido" (GRAMSCI, 1981, p. 143).

Trazer essas discussões acerca do pensamento gramsciano para o campo da formação em Educação Física tem o objetivo precípuo de alertar, no plano teórico, que a nossa prática cotidiana é condicionada por fatores conjunturais e possui nexos que articulam as ações humanas, sendo que a especificidade de cada fenômeno, como uma prática corporal, por exemplo, não pode ser vista como uma contingência singular, mas articulada com processos mais amplos que a condicionam. Afinal, como diz a cantiga de entrada. A vida é ...também um jogo, é uma luta, é o corpo arrepiado...

Ao avaliar o processo de formação em Educação Física, num plano mais geral, necessário se faz uma articulação desta com os movimentos do cotidiano e com as práticas corporais populares e comunitárias. A Educação Física precisa "dialo(jo)gar" 4 com as manifestações culturais populares, pois nelas estão expressas, ou latentes as reais necessidades da maioria da população, que ainda vive em condições desastrosas.

Em artigo, publicado na Revista Brasileira de Ciências do Esporte (RBCE), (FALCÃO, 2007), analisamos os indicadores da produção do conhecimento no campo da Educação Física brasileira e constatamos que, embora expressiva, a produção do conhecimento nesse campo

\footnotetext{
${ }^{4}$ Termo utilizado por Silva (2006).
} 
ainda continua sendo pautada por modelos empírico-analíticos e distanciada dos movimentos e jogos da cultura popular.

Diante desse quadro, poderíamos perguntar, então: quais possibilidades para novas formulações no campo da formação em Educação Física, considerando a política, o corpo, a cultura e o cotidiano, todos eles inseridos e influenciados em escala global na lógica do capitalismo eletrônico-informático transnacional ${ }^{5}$ ?

São questões difíceis de serem respondidas. Para contribuir com a problematização dessas mesmas questões, no intuito de buscar alternativas para compreendê-las e, com isso, aventar possíveis respostas, trazemos a baila aspectos do debate sobre a questão da cultura nas ciências sociais, utilizando como suporte algumas contribuições do sociólogo francês Denys Cuche, que atualmente desenvolve seus estudos na Universidade de Paris Descartes.

Quando falamos de cultura sabemos que se trata um termo polissêmico, ou seja, existem muitas concepções de cultura. É um conceito que provoca mais perguntas que respostas. Entretanto, não podemos desprezar a sua conceptualização original que é proveniente do latim colere $^{6}$, que quer dizer cultivar: trabalhar a terra, semear, colher (agricultura), onde a mesma nasce onde os homens produzem a base de sua vida. Nessa perspectiva, o fazer cultural constitui-se numa extensão da própria vida.

O debate acerca do conceito de cultura se revela, portanto, enriquecedor para questionar as explicações naturalizantes dos comportamentos. Para Denys Cuche, a natureza, no homem, é inteiramente interpretada pela cultura. Só que ela não pode ser manipulada como "um instrumento vulgar, pois ela está relacionada a processos extremamente complexos e, na maior parte das vezes, inconscientes”. (CUCHE, 2002, p. 15).

Nas formulações de Cuche (2002), o que mais nos chama atenção em relação ao conceito de cultura é sua estreita relação com o conceito de identidade, tão polissêmico quanto aquele. Sinteticamente, para esse autor existem duas abordagens ou concepções que tratam da identidade no campo das ciências Sociais. As concepções "objetivistas" e "subjetivistas". Os signatários da concepção objetivista defendem que a identidade de um indivíduo é a herança cultural recebida do seu grupo original, como uma espécie de "segunda natureza" da qual ele não pode escapar. Em suas palavras, corresponde à "origem, as raízes, segundo a imagem comum, isto é, aquilo que definiria o indivíduo de maneira autêntica"

\footnotetext{
${ }^{5}$ Cabe aqui um esclarecimento acerca do tema transnacional que, por sua vez, refere-se a um nível de integração de populações que cria um novo modo de representar pertencimento a unidades sociopolíticas e culturais. O fato é que hoje não dá mais para discutir o conceito de cultura sem incorporar o conceito de transnacional.

${ }^{6} \mathrm{O}$ conceito de cultura é bastante discutido pelas Ciências Sociais e ao longo da história recebeu diferentes significados. Ver, por exemplo, Chaui (1989), Laraia (1986).
} 
(CUCHE, 2002, p. 178). Nesse caso, a identidade seria pré-existente ao indivíduo que não teria alternativa senão aderir a ela, sob o risco de se tornar um marginal, um "desenraizado".

Entre outros problemas, essa formulação pode levar a "racialização" dos indivíduos, pois para algumas teses radicais, a identidade está praticamente inscrita no patrimônio genético do indivíduo. Essa concepção objetivista pode se desdobrar numa abordagem culturalista, em que a ênfase não é colocada sobre a herança biológica, mas sobre a herança cultural. Nesse caso, o indivíduo é levado a interiorizar os modelos culturais que lhes são impostos até o ponto de se identificar com o seu grupo de origem. Para tal, arbitram determinadas "invariantes culturais" que permitem definir a essência do grupo, ou seja, sua identidade, "essencial" praticamente invariável (CUCHE, 2002).

Outra variante dessa concepção objetivista de identidade é chamada de "primordialista". Nesse caso, consideram que a identidade etno-cultural é primordial porque a vinculação ao grupo étnico é a primeira e a mais fundamental de todas as vinculações sociais. É no grupo étnico onde se partilham as emoções e as solidariedades mais profundas e mais estruturantes.

Essas concepções objetivistas de identidade têm um traço comum. Tratam as identidades a partir de certo número de critérios determinantes considerados como objetivos, como a origem comum, a língua, o território comum. Tais concepções são bastante questionadas pelos que defendem uma abordagem subjetivista de identidade. Para os defensores dessa perspectiva, a identidade não pode ser reduzida a sua dimensão atributiva. Ela não passa de um sentimento de identificação ou de vinculação a uma coletividade imaginária, em maior ou menor grau. Sendo assim, nessa perspectiva, o importante são as representações que os indivíduos fazem da realidade social e de suas divisões.

A rigor, o ponto de vista dos subjetivistas levado ao extremo leva à redução da identidade a uma questão de escolha individual arbitrária em que cada um seria livre para escolher suas identificações. Isso pode ser analisado como uma elaboração puramente fantasiosa, nascida da imaginação de alguns ideólogos que manipulam as massas crédulas, buscando objetivos nem sempre confessáveis.

Para Cuche (2002), essa visão subjetivista tem o mérito de considerar o caráter variável das identidades, apesar de ter a tendência de enfatizar excessivamente seu aspecto efêmero. Não é raro, no entanto que as identidades sejam relativamente estáveis.

Adotar uma abordagem puramente objetiva ou puramente subjetiva para tratar a questão da identidade pode desencadear conflitos incontornáveis. Nesse sentido Cuche (2002) propõe a abordagem "relacional e situacional de identidade" e defende ainda que não existe uma identidade em si, nem mesmo unicamente para si. A identidade é sempre relacional, daí sugere ser preferível utilizar o termo identificação. 
A identificação pode funcionar como afirmação ou como imposição da identidade. A identidade é sempre uma concessão, uma negociação entre uma auto identidade e uma heteroidentidade, ou uma exo-identidade definida pelos outros (SINSON, apud CUCHE, 2002).

Se a cultura depende em grande parte dos processos inconscientes, a identidade remete a uma norma de vinculação, necessariamente consciente, baseada em oposições simbólicas.

Por fim gostaríamos de ressaltar que o papel do intelectual não é fazer a defesa das identidades. Para Cuche (2002, p. 187):

Não é a sociologia ou a antropologia, nem a história ou outra disciplina que deverá dizer qual seria a definição exata da identidade bretã ou da identidade kabyla, por exemplo. Não é á sociologia que deve se pronunciar sobre o caráter autêntico ou abusivo de tal identidade particular. Não é o cientista que deve fazer 'controle de identidades'. O papel do cientista é outro. Ele tem o dever de explicar os processos de identificação sem julgá-los.

Essa discussão sobre política, cultura e identidade ao ser traduzida na prática por intermédio da intervenção pedagógica no cotidiano da Educação Física, deve levar em consideração que a realidade é uma construção sempre complexa que se materializa com determinações, conflitos, ambivalências, conformismos e resistências.

Os fenômenos culturais, ao serem materializados no cotidiano, colocam em jogo todas essas questões. Como então lidar com essa complexidade? Para problematizar essas questões trazemos aqui para esse jogo as contribuições do sociólogo português Machado Pais (2002), quando trata da sociologia da vida cotidiana. Antes, porém questionamos: Quais seriam as razões que explicariam o deslocamento da atenção sociológica dos grandes dispositivos e sistemas sociais para os espaços da vida cotidiana e dos modos de vida? A análise do cotidiano estaria atrelada a uma inevitável micro-sociologia? Vida quotidiana e história são irreconciliáveis? De que modo e em que medida as ações interindividuais, em determinadas condições, renegam as estruturas mais gerais da sociedade? Como capturar o fugaz da realidade, a pluralidade infinita de detalhes da vida social que a sociologia tradicional renuncia em captar? E como transformar o "familiar" no "exótico" que leva ao estranhamento dessa realidade aparentemente tão familiar, mas, na verdade, tão enigmática?

Para responder essas questões Machado Pais argumenta que o trilhar sociológico pelas rotas do cotidiano não obedece a uma lógica de "demonstração", mas antes a uma lógica de "descoberta". A sociologia da vida cotidiana incorpora um movimento de novos saberes e sensibilidades, em contraponto ao positivismo "etnocêntrico" de algumas formas "canônicas" da sociologia tradicional que abrigam pesquisadores aprisionados aos seus credos doutrinários de suas "escolas ou guetos metodológicos". A lógica de descoberta, que caracteriza a sociologia da vida cotidiana, não é compatível com o "pré-estabelecido" e com a “domesticação de itinerários" herméticos e pré-determinados. 
A descoberta dos enigmas do cotidiano, ao valorizar a busca por detalhes, por meio de estudos do tipo etnográfico, rejeita a sua submissão às perspectivas teóricas macrossociológicas. Defende, em contrapartida, a necessidade da sociologia da vida cotidiana explorar as relações dialéticas entre a microanálise e a microanálise no estudo articulado de comportamentos e estruturas sociais.

Ao discutir a contextualização sociológica pela via do cotidiano, Machado Pais propõe um debate sobre a necessária redefinição da noção de "contexto". Chama a atenção para a importância dos contextos vivenciais dos indivíduos para clarificar ou informar os contextos sociológicos (analíticos, interpretativos, explicativos) usados pelas teorias. Busca ver a sociedade em nível dos indivíduos e tentar uma explicação de como a sociedade se traduz na vida deles.

Pensar a categoria cotidiano nesse imenso país chamado Brasil é vislumbrar as potencialidades e intensidades de milhares de manifestações culturais das mais distintas matizes que grassam o dia-a-dia de comunidades metropolitanas, quilombolas, indígenas, ribeirinhas e tantas outras, que, por sua vez, formam o manancial cultural onde os processos de escolarização formal deveriam tomar como principal fonte de referência.

Após articular esses conceitos, ainda que minimamente, cabe aqui fechar com a necessária retomada das contribuições teóricas do mundialmente conhecido educador brasileiro, Paulo Freire, o pedagogo dos oprimidos, que durante toda a sua vida nos legou uma importante proposta de Educação como prática de liberdade e que vem sendo esquecida, repelida e amaldiçoada pela mídia senso comum, travestida de bom senso, como foi o caso da Edição n. 20 da Revista Veja, de 20 de agosto de 2008, que, por intermédio de suas articulistas Monica Weinberg e Camila Pereira, destaca, numa linguagem rasteira e irresponsável, que Paulo Freire não passa de um personagem obsoleto sem contribuição efetiva à civilização ocidental.

As contribuições teóricas de Paulo Freire são dramaticamente atuais e servem de subsídios para o trato com o conhecimento de diversos conteúdos e áreas do conhecimento. $\mathrm{Na}$ esteira do pensamento de Gramsci, Paulo Freire defendia que a ação cultural para a liberdade dos oprimidos deveria ser formulada em conformidade com a realidade em que viviam.

A pedagogia do oprimido, em especial, constitui, no contexto de suas reflexões sobre a cultura dos explorados, o processo pelo qual os homens e as mulheres são formados/humanizados. Essa é a obra mais importante de Freire, porque nela está esboçada, de forma global, a síntese da relação que se estabelece no "estar no mundo dos homens". A sua visão antropológica de ser humano aí presente é a descrição da forma como os homens encontram-se nas relações que estabelecem, de forma contraditória e necessária. 


\section{CONSIDERAÇÕES FINAIS}

Diante do exposto, tratar o campo de formação em Educação Física, levando em consideração todas essas questões discutidas, requer, primeiramente, um questionamento da hegemonia das propostas educacionais fundamentadas em abordagens objetivas e subjetivas de identidade, que, por sua vez, geram pedagogias de assimilação. A Pedagogia, num sentido amplo, precisa inovar e acompanhar o desenvolvimento da sociedade, como os avanços na área da linguagem e da comunicação, por exemplo, instaurados pelas chamadas novas tecnologias. Não se trata de uma vontade de inovar, mas sim de uma necessidade social de inovação.

Não há mais lugar para as pedagogias de assimilação, onde o aluno vai à escola ou universidade aprender representações, conceitos e conteúdos previamente determinados pelo professor. Ao professor cabe a responsabilidade de fazer uma análise crítica da informação e orientar os alunos a andar num labirinto de infinitas possibilidades geradas pelo avanço da automação e pelas novas redes de comunicação. Por mais que tente, não há professor capaz de repassar ao aluno todo o conteúdo divulgado atualmente, no âmbito de uma determinada disciplina. Introduzindo o aluno no labirinto, o professor ressalta as singularidades e possibilita, num espaço de diferenças, a experiência com as multiplicidades históricas, coletivas e individuais.

Embora não possamos negar os processos de dominação cultural, não há mais lugar para as pedagogias hegemônicas universais, nem tampouco para as propostas inovadoras de toque de caixa. Uma palavra fundamental nesta dinâmica é a instabilidade. As instabilidades são localizadas e se diluem para dar lugar a outras, infinitamente.

É preciso considerar a necessidade de viver a diferença, e cultivar a diferença é viver num universo virtual de possibilidades. É a linguagem que dá sentido à realidade. Nessa perspectiva, o elemento fundante é o espaço de infinitas possibilidades. Portanto, a diferença é indizível, porque só é dizível quando se agencia através das diversas formas de linguagem que dão sentido aos acontecimentos.

$\mathrm{Na}$ trilha dessas proposições, propugnamos que a formação em Educação Física abdique de relações causais e de regularidades, e passa a adotar o acontecimento, o improvável, o acaso, enfim, as infinitas possibilidades de jogo que se acometem no cotidiano, articuladas com o movimento mais geral da sociedade.

O acontecimento, pela sua identificação com a singularidade, a contingência e o acidente, foi por muito tempo expulso, não apenas das ciências naturais, mas também das ciências humanas, que tendem a arrumarem-se em torno de leis, modelos, estruturas e 
sistemas. Até a história tende a expulsar o acontecimento. Trata-se de incorporá-lo e considerá-lo parte do próprio sistema. $\mathrm{O}$ acontecimento historiciza a natureza.

As contribuições dos pensadores Gramsci, Cuche, Machado Pais e Freire, esboçadas nesse texto, podem e devem ser tratadas de forma articulada. Suas elaborações podem servir de ferramenta para uma intervenção crítica no campo da formação em Educação Física.

Seguindo seus ensinamentos e exemplos, condenando a educação bancária como fez Paulo Freire, se enfronhando com os explorados na luta por uma sociedade melhor, como o fez Gramsci, capturando a pluralidade infinita do cotidiano social, como o fez Machado Pais e alertando para os processos identitários sempre relacionais, como o fez Cuche, poderemos contribuir, como intelectuais orgânicos, em favor dos oprimidos, no enfrentamento das barbáries de todas as ordens que assolam a política, o cotidiano, e, consequentemente, o processo de formação no campo da Educação Física no Brasil.

\section{REFERÊNCIAS}

CHAUI, Marilena. Conformismo e resistência: aspectos da cultura popular no Brasil. 3. ed. São Paulo: Brasiliense, 1989.

CUCHE, Denys. A noção de cultura nas ciências sociais. 2. ed. Bauru: EDUSC, 20002.

FALCÃO, José Luiz Cirqueira. A produção do conhecimento na educação física brasileira e a necessidade de diálogos com os movimentos da cultura popular. Revista Brasileira de Ciências do Esporte. Campinas, v. 29. n. 1, p. 143-161, 2007.

FREIRE, Paulo. Educação como prática de liberdade. 18. ed. Rio de Janeiro: Paz e Terra, 1983.

FREIRE, Paulo. Pedagogia do oprimido. 17. ed. Rio de Janeiro: Paz e Terra, 1987.

GRAMSCI, Antonio. Concepção dialética da história. 4. ed. Rio de Janeiro: Civilização Brasileira, 1981.

LARAIA, Roque de Barros. Um conceito antropológico de cultura. Rio de Janeiro: Jorge Zahar Editora, 1986.

LEFEBVRE, Henri. A vida cotidiana no mundo moderno. Trad. Alcides João de Barros. São Paulo: Ática, 1991.

MACHADO PAIS. José. Sociologia da vida quotidiana. Lisboa: Instituto de Ciências Sociais, 2002. 
MÉSZÁROS, Istvan. Para além do capital: rumo a uma teoria da transição. São Paulo: Boitempo, 2002.

SANTOS, Milton. Por uma outra globalização: do pensamento único à consciência universal. 4. ed. Rio de Janeiro: Record, 2000.

SILVA, Bruno Emmanuel Santana. Menino qual é teu mestre? capoeira pernambucana e as representações sociais dos seus mestres. 2006. Dissertação (Mestrado em Educação Física) Universidade Federal de Santa Catarina, Florianópolis, 2006.

TAFAREL, C. N. Z. Epistemologias e teorias do conhecimento na pesquisa em Educação e Educação Física: as reações aos pós-modernismos. In: Rascunho Digital. Disponível em:: <www.faced.ufba.br/rascunhodigital/ >. Acesso em: 05 ago. 2009. 